Rev. Adm. Saúde - Vol. 18, № 70, jan. - mar. 2018

http://dx.doi.org/10.23973/ras.70.74

CARTA À REDAÇÃO

\title{
Gestão em saúde e escolas médicas: estudantes de medicina como futuros gestores
}

Health management and medical schools: medical students as future managers

\author{
Luis Arthur Brasil Gadelha Farias ${ }^{1}$
}

1. Acadêmico de quinto ano de medicina na Faculdade de Medicina, Universidade Federal do Ceará (UFC), Fortaleza, Ceará

Segundo as diretrizes curriculares nacionais, são preconizadas competências para o médico em formação. Tais competências relacionam-se com a capacidade de mobilizar conhecimentos, habilidades e atitudes com o intuito de resolver problemas e situações reais, de modo que seja possível sua atuação profissional. Não obstante, pontua-se como competência geral a administração e gerenciamento com ênfase na aptidão do profissional em gerenciar e administrar tanto a força de trabalho, os recursos físicos, materiais e informacionais, como serem gestores, empregadores ou líderes na equipe de saúde ${ }^{1,2}$

Fato é que elementos do mercado se associam fortemente com a formação de competências em qualquer âmbito e ciência. $O$ mercado de trabalho no mundo globalizado exerce forte influência sobre a universidade e, por conseguinte, no direcionamento e formação do profissional do futuro. Desse modo, a gestão em saúde, como competência médica, assume grande importância e se destaca como um objetivo da formação com o objetivo de alcançar uma prática eficaz, capaz não somente de solucionar problemas, mas também de melhorar os contextos sociais por meio de uma gestão responsável e uso eficiente dos recursos.

O questionamento que surge é de que forma esta competência vem sendo inserida nos currículos das escolas médicas pelo Brasil. São noções básicas, porém imprescindíveis, como o gerenciamento de pessoas e recursos, que podem não estar sendo fornecidas para os nossos alunos. Esta pergunta vem à tona num contexto social e de saúde nacional alarmantes, em que a correta gestão tem se mostrado ponto chave nesse dilema ${ }^{3}$. 
As publicações envolvendo a temática gestão em saúde e escolas médicas são escassas. Utilizando a base de dados nacional LILACS e inserindo os descritores "gestão em saúde" e "currículo médico", com o tema "currículo" como assunto principal, é possível encontrar apenas 7 artigos, dos quais 6 não possuem relação com a temática. Carvalho et al., entretanto, propõe reflexões acerca do ensino da gestão em saúde no internato de medicina da Faculdade de Ciências Médicas da Universidade Estadual de Campinas, e conclui acerca da importância dos assuntos gestão em saúde, gestão da clínica médica, gestão do cuidado e gestão em rede no curso médico e acerca da necessidade de novos estudos que aprofundem o tema ${ }^{4}$.

Por fim, suscito a importância do envolvimento do acadêmico em medicina na busca pelo ensino e inserção das ciências da gestão no curso médico. A participação do discente é fundamental para o cumprimento das diretrizes curriculares nacionais pelas faculdades de medicina do país, devendo o ensino de gestão estar presente desde o ensino básico ao avançado, tão importante quanto o conhecimento biomédico, ético e como parte integrante do desenvolvimento pessoal e social. Afinal, os estudantes de medicina constituirão, junto aos profissionais das outras áreas da saúde, futuros gestores.

\section{REFERÊNCIAS}

1. Brasil. Ministério da Educação. Diretrizes Curriculares Nacionais do Curso de Graduação em Medicina [acesso 2017 set 20]. Disponível em: http://portal.mec.gov.br/cne/arquivos/pdf/Med.pdf

2. Brasil. Ministério da Educação e Cultura. Conselho Nacional de Educação. Resolução CNE/CES N44, de 7 de novembro de 2001. Institui Diretrizes Curriculares Nacionais do Curso de Graduação em Medicina [acesso em 2018 jan 04]. Disponível em: http://portal.mec.gov.br/cne/arquivos/pdf/CES04.pdf

3. Amoretti R. A educação médica diante das necessidades sociais em saúde. Revista Brasileira de Educação Médica. 2005; 29(2): 136-146.

4. Carvalho SR, Campos GWS, Oliveira GN. Reflexões sobre o ensino de gestão em saúde no internato de medicina na Faculdade de Ciências Médicas da Universidade Estadual de Campinas: Unicamp. Interface (Botucatu) [acesso em 2018 Jan 04]. 2009;13(29): 455-465. Disponível em: http://www.scielo.br/scielo.php?script=sci_arttext\&pid=S1414$32832009000200017 \& \operatorname{lng}=e n$ 
Recebido: 04 de janeiro de 2018. Publicado: 12 de janeiro de 2018

Correspondência: Luis Arthur Brasil Gadelha Farias. E-mail:

luisarthurbrasilk@hotmail.com

Conflito de Interesses: o autor declarara não haver conflito de interesses.

(C) This is an Open Access article distributed under the terms of the Creative Commons Attribution License, which permits unrestricted use, distribution, and reproduction in any medium, provided the original work is properly cited 
